\title{
Adsorption of C.I. Acid Red 97 dye from aqueous solution onto walnut shell: kinetics, thermodynamics parameters, isotherms
}

\author{
H. S. Ghazi Mokri • N. Modirshahla • \\ M. A. Behnajady $\cdot$ B. Vahid
}

Received: 3 April 2014/Revised: 30 October 2014/Accepted: 22 November 2014/Published online: 11 December 2014

(C) Islamic Azad University (IAU) 2014

\begin{abstract}
This study aims to investigate the adsorption of C.I. Acid Red 97 (AR97) onto walnut shell (WS) in order to find out the desired conditions. The effect of operational parameters including adsorbent dosage, agitation speed, contact time, $\mathrm{pH}$ and temperature was studied in a batch mode. The results revealed that $73.33 \%$ of AR97 $(50 \mathrm{mg} /$ L) was decolorized at $60 \mathrm{~min}$ of contact time, agitation rate of $140 \mathrm{rpm}$ and $12 \mathrm{~g} / \mathrm{L}$ of adsorbent at $291 \mathrm{~K}$. The rate of adsorption follows pseudo-second-order kinetics with the high correlation coefficient, which was more than 0.99 . Specific surface area of WS was calculated as $1.28 \mathrm{~m}^{2} / \mathrm{g}$ by BET method. It was observed from the values of thermodynamics parameters such as Gibbs free energy $\left(\Delta G^{\circ}\right)$, enthalpy $\left(\Delta H^{\circ}\right)$ and entropy $\left(\Delta S^{\circ}\right)$ that the nature of adsorption process is spontaneous, exothermic and mainly physical. Langmuir, Fruendlich and Redlich-Peterson isotherms were applied for mathematical description of equilibrium data and findings indicated that it is in good agreement with Fruendlich model.
\end{abstract}

Keywords C.I. Acid Red 97 - Adsorption - Walnut shell · Kinetics · Thermodynamics parameters · Isotherm

\footnotetext{
H. S. Ghazi Mokri $(\bowtie) \cdot$ N. Modirshahla $\cdot$ M. A. Behnajady Department of Chemistry, College of Science, Tabriz Branch, Islamic Azad University, Tabriz, Iran

e-mail: h.ghazi64@gmail.com

B. Vahid

Young Researchers and Elite Club, Tabriz Branch, Islamic Azad University, Tabriz, Iran
}

\section{Introduction}

Dyes and pigments play the essential role in the textile industry, and nowadays, approximately 10,000 of dyes were used in textile industry, besides they are significant in the industrial chemistry (Behnajady et al. 2007; Daneshvar et al. 2004). Discharging of these dyes up to $10 \%$, during their production and consumption into water supplies, can create various problems. It can affect food and water cycles, and also cause allergic dermatitis and skin sensitivity. Moreover, these dyes can be toxic and hazardous and cause mutation for watery organisms (Doğan et al. 2009). Cationic (basic dyes), anionic (direct, acid and reactive dyes) and nonionic (disperse) are three types of dyes (Mall et al. 2006). Over $50 \%$ of all textile dyes utilized in the industries are azo dyes (Behnajady et al. 2006). The chemical structure of these dyes can be defined as single or multiple units of azo $(-\mathrm{N}=\mathrm{N}-)$ bonds connected to aryl or naphthalene groups, it creates chromophore feature in them (Ince and Tezcanli-Güyer 2004). The major problem for the industries and also for environment is treatment of these colored wastewaters (Behnajady et al. 2008).

In recent years, many methods including coagulation and flocculation (Furlan et al. 2010), reverse osmosis (Gupta et al. 1990), chemical oxidation (Neamtu et al. 2004), biological treatment (Ledakowicz et al. 2001), photodegradation (Behnajady et al. 2006) and adsorption (Rafatullah et al. 2010) have been developed for treating of dyes in wastewaters. Among these methods, adsorption has become proper method for treatment of aqueous effluent (Nandi et al. 2009a, b).

Activated carbon owing to its high surface area and high adsorption capacity is one of the common adsorbents. However, it is uneconomical for industrial application due 
to its high price; so, the process of dye removal through adsorption can be economically feasible by substituting low-cost adsorbents (Nandi et al. a, b; Demirbas 2009; Dural et al. 2010). For this reason, researches have focused on the usage of low-cost, locally available, reusable, biodegradable adsorbents made from natural sources like rice hull shell (Wang et al. 2010), wood apple shell (Jain and Jayaram 2010), fly ash (Sun et al. 2010) and powdered peanut hull (Gong et al. 2005). Natural and modified clays like sepiolite (Eren et al. 2010), zeolite (Mustafaa et al. 2010), perlite (Doğan et al. 2004) and bentonite ( $\mathrm{Li}$ et al. 2010) are being considered as alternative low-cost adsorbents (Rafatullah et al. 2010).

Adsorption experiments using walnut shell (WS) as an adsorbent have been reported on other dyes like malachite green (Dahri et al. 2014), reactive brilliant red K-2BP (Cao et al. 2014) and heavy metals such as $\mathrm{Cr}$ (VI) (Altun and Pehlivan 2012). But from the survey of the literature, no information for the adsorption removal of Acid Red 97 (AR97) by WS is available. The objective of this study was to investigate the effectiveness of WS for the removal of AR97 from aqueous solutions in a batch mode. Then, the effect of operational parameters including adsorbent dosage, agitation speed, contact time, $\mathrm{pH}$ and temperature was investigated on the adsorption process. Eventually, the applicability of known adsorption isotherms and kinetic models, and also thermodynamic parameters was studied.

\section{Materials and methods}

\section{Materials}

The azo acid dye, AR97 (C.I. 22890, FW: 698.63274 and $\lambda_{\max }: 498 \mathrm{~nm}$ ) is a biorefractory contaminant but commonly used in the textile and tanning industries supplied by Aldrich, USA. Due to these characteristics, it was selected as a model adsorbate (Kayan et al. 2010). Its molecule exists as an anion in aqueous medium. The walnut shell as an adsorbent was provided from Mahabad region in Iran. It was ground up by hand mill and used after sieving as an adsorbent, and other chemicals were purchased from Merck Company in Germany.

\section{Experimental methods}

The experiments were performed in a batch mode, using AR97 solution with concentration of $50 \mathrm{mg} / \mathrm{L}$. Stock solution of AR97 was prepared by dissolving proper amount of dye in distilled water. Experimental solution with the desired concentration was obtained by dilution. The experiments were carried out by feeding $50 \mathrm{~mL}$ of solution with known concentration of the dye into a
$100 \mathrm{~mL}$ Erlenmeyer, and certain amount of the adsorbent was added and agitated for distinct time at known speed by shaker. At the end of the time, the sorbent was centrifuged and the adsorption of dye solution was determined by UV/ Vis spectrophotometer. The dye removal efficiency can be calculated as follows:

$\%$ dye removal $=\frac{\left(C_{\mathrm{o}}-C\right)}{C_{\mathrm{o}}} \times 100$

where $C$ is the concentration of dye at any time $(t)$, and $C_{\mathrm{o}}$ is the initial dye concentration in the solution $(\mathrm{mg} / \mathrm{L})$. In order to study the sorption isotherms, the amount of adsorbed dye at equilibrium, $q_{\mathrm{e}}(\mathrm{mg} / \mathrm{g})$, and at time $t, q_{t}$ $(\mathrm{mg} / \mathrm{g})$, was calculated by:

$q_{\mathrm{e}}=\frac{\left(C_{\mathrm{o}}-C_{\mathrm{e}}\right) V}{W}$

$q_{\mathrm{t}}=\frac{\left(C_{\mathrm{o}}-C_{t}\right) V}{W}$

where $C_{\mathrm{e}}$ is the equilibrium dye concentration $(\mathrm{mg} / \mathrm{L}), W$ is the adsorbent mass (g) and $V$ is the volume of the solution (L) (Mall et al. 2006).

\section{Results and discussion}

\section{Characterization of WS}

The nitrogen adsorption-desorption isotherm at $77 \mathrm{~K}$ onto WS is shown in Fig. 1, which is in correspondence with classical type III isotherm of IUPAC classification (Sing

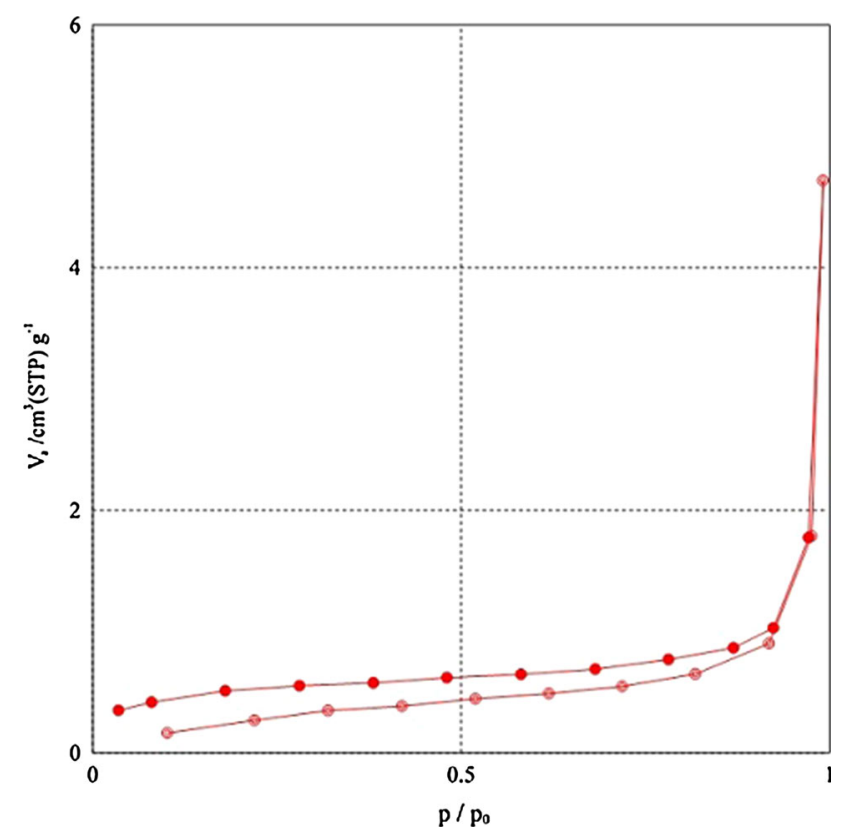

Fig. 1 Physisorption isotherm of WS 
et al. 1985). According to the results of BET method, the average specific surface area and total pore volume of WS were $1.28 \mathrm{~m}^{2} / \mathrm{g}$ and $6.89 \times 10^{-3} \mathrm{~cm}^{3} / \mathrm{g}$, respectively. The adsorption capacity of WS depends on porosity and chemical reactivity of functional groups at the surface. Knowledge on surface functional groups would give insight into the adsorption capability of the WS (Senthil Kumar et al. 2010). The FT-IR analysis for WS showed broad band near $3,435 \mathrm{~cm}^{-1}$, which indicates the presence of hydroxyl groups on the WS surface.

Effect of adsorbent dose

The adsorption of the AR79 dye onto the WS was studied by varying the dosage of the adsorbent $(0.1-1.2 \mathrm{~g})$ at dye concentration of $50 \mathrm{mg} / \mathrm{L}$. The effect of WS dose on the adsorption of AR97 is shown Fig. 2. The removal percent enhanced with increasing WS amount up to a certain limit $(0.6 \mathrm{~g})$, and then, it remained approximately constant. This behavior can be attributed to availability of more adsorption sites and greater surface area (Nandi et al. 2009a, b).

\section{Effect of agitation speed}

Adsorption process strongly depends on agitation speed owing to the distribution of the solute in the solution and the formation of the external boundary film. Figure 3 demonstrates the removal percent of AR97 $(50 \mathrm{mg} / \mathrm{L})$ at different agitation speeds (80-180 rpm) within contact time of $1 \mathrm{~h}$. From the figure, it is clear that with increasing agitation speed, the percentage removal of dye enhanced from 50.08 to $73.95 \%$. The increase in removal percentage can be described by the fact that increasing agitation speed reduces the film boundary layer and surrounding particles, therefore increasing the external film transfer coefficient (Nandi et al. 2009a, b).

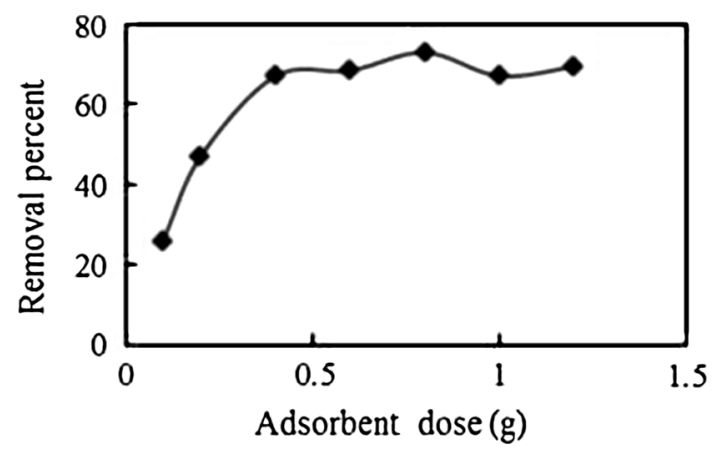

Fig. 2 Effect of adsorbent dose on the removal percentage of AR97. $([$ AR97] $=50 \mathrm{mg} / \mathrm{L}, T=297 \mathrm{~K}$, agitation speed $=120 \mathrm{rpm}, \mathrm{pH}=5.45$ )

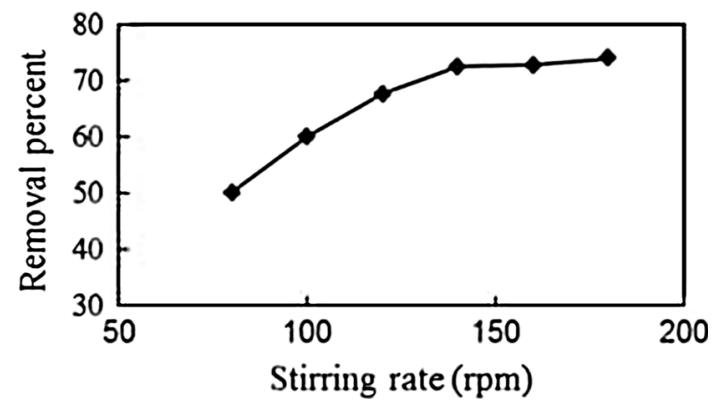

Fig. 3 Effect of agitation speed on the percentage removal of AR97 by WS. ([AR97] $=50 \mathrm{mg} / \mathrm{L}, T=293 \mathrm{~K}$, adsorbent dose $=12 \mathrm{~g} / \mathrm{L}$, $\mathrm{pH}=5.45)$

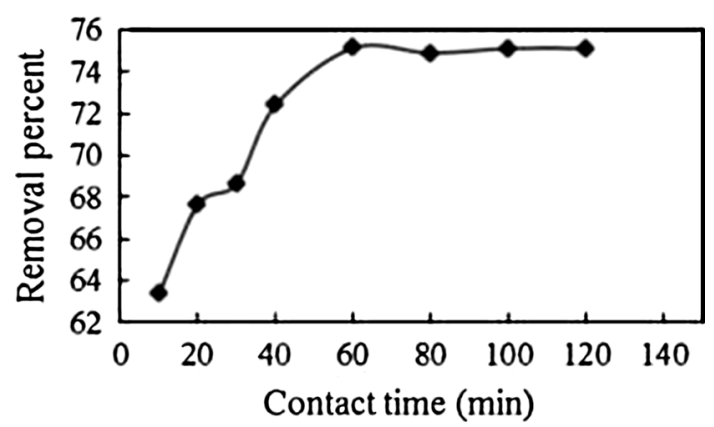

Fig. 4 Effect of contact time on the removal percentage of AR97 by WS. $([$ AR97] $=50 \mathrm{mg} / \mathrm{L}, T=298 \mathrm{~K}$, agitation speed $=140 \mathrm{rpm}$, adsorbent dose $=12 \mathrm{~g} / \mathrm{L}, \mathrm{pH}=5.45$ )

\section{Effect of contact time}

The mixture of $0.6 \mathrm{~g}$ of the adsorbent and $50 \mathrm{~mL}$ of the dye solution $(50 \mathrm{mg} / \mathrm{L})$ was agitated at various times. It is obvious from Fig. 4 that the maximum amount of dye removal took place within the contact time of $60 \mathrm{~min}$, and then, it remained almost constant due to the desorption process and the solution that has reached equilibrium (Govindasmay et al. 2009). The fast adsorption at the initial contact time can be explained by the electrostatic attraction, and the slow rate of dye adsorption after 60 min may occur as a result of the slow pore diffusion of the solute molecules into the bulk of the adsorbent (Khaled et al. 2009).

\section{Point of zero charge measurements and Effect of $\mathrm{pH}$}

It is essential to realize the adsorption mechanism by determining the zero point charge $\left(\mathrm{pH}_{\mathrm{ZPC}}\right)$ of the adsorbent (Govindasmay et al. 2009). The $\mathrm{pH}_{\mathrm{ZPC}}$ of the WS was measured by $\mathrm{pH}$ drift method. It was performed by adjusting the $\mathrm{pH}$ of a solution containing $0.01 \mathrm{M} \mathrm{NaCl}$ between 2 and 12 using $\mathrm{NaOH}$ and $\mathrm{HCl}$, and then, $0.1 \mathrm{~g}$ of WS was added to $50 \mathrm{~mL}$ of the solution. The final $\mathrm{pH}$ was recorded after stabilizing the initial $\mathrm{pH}$ after $24 \mathrm{~h}$. The 


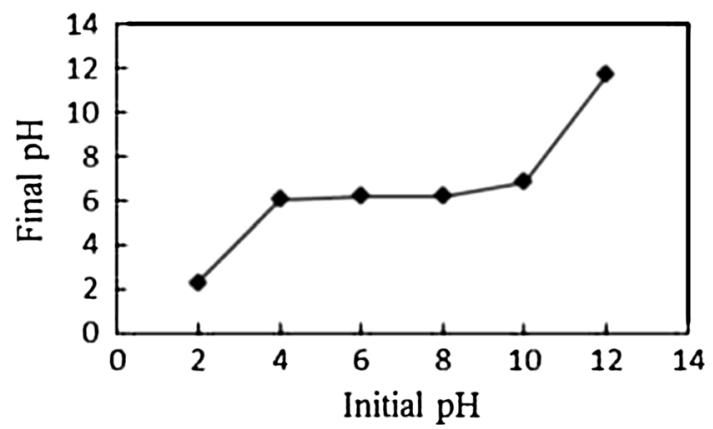

Fig. 5 Zero point charge $\left(\mathrm{pH}_{\mathrm{ZPC}}\right)$ of the WS used for the adsorption experiments

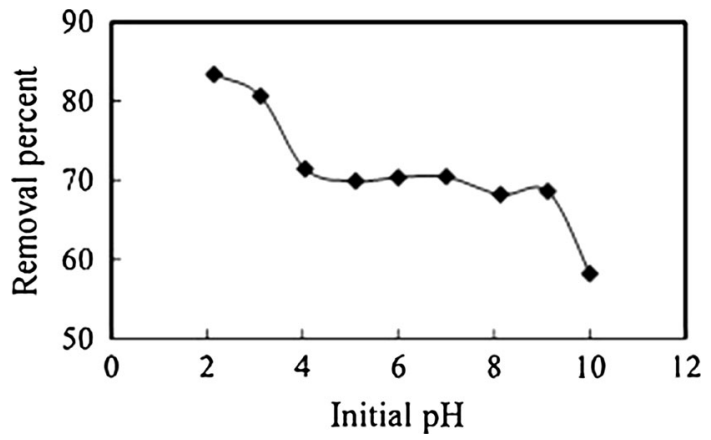

Fig. 6 Effect $\mathrm{pH}$ on the removal percentage of AR97 by WS. (contact time $=60 \mathrm{~min}, T=292 \mathrm{~K}$, agitation speed $=140 \mathrm{rpm}$, adsorbent dose $=12 \mathrm{~g} / \mathrm{L}, \mathrm{pH}=5.45$ )

graph of final $\mathrm{pH}$ versus initial $\mathrm{pH}$ was used to identify $\mathrm{pH}_{\mathrm{ZPC}}$ that is the point in which both initial and final $\mathrm{pH}$ values are equal (Govindasmay et al. 2009). In this study, the $\mathrm{pH}_{\mathrm{ZPC}}$ of the WS was found to be 6.18 (Fig. 5).

The $\mathrm{pH}$ of dye solution is an effective parameter, which controls the adsorption particularly the adsorption capacity. Adsorption of anions is favored at lower $\mathrm{pH}\left(<\mathrm{pH}_{\mathrm{zpc}}\right)$, while the adsorption of cations is favored at a higher $\mathrm{pH}$ $\left(>\mathrm{pH}_{\mathrm{zpc}}\right)$ (Govindasmay et al. 2009). The results indicated that acidic $\mathrm{pH}$ supported the adsorption of negatively charged AR97 (an anionic dye) on WS, where the surface change of WS was positive (Fig. 6).

\section{Adsorption isotherm study}

Adsorption isotherms are mathematical models that the equilibrium studies have an essential role in optimizing the design parameters for adsorption system. They provide adequate information on the physicochemical data of the adsorption process as a unit operation. In order to find a suitable model that can be utilized for design process, equilibrium data should appropriately fit into diverse isotherm models. The purpose of the adsorption isotherm
Table 1 The value of parameters for each isotherm models used in the studied

\begin{tabular}{llll}
\hline \multicolumn{2}{l}{ Langmuir nonlinear } \\
\hline Equation & $K_{\mathrm{L}}(\mathrm{L} / \mathrm{mg})$ & $q_{\mathrm{m}}(\mathrm{mg} / \mathrm{g})$ & $R^{2}$ \\
\hline$q_{\mathrm{e}}=\frac{q_{\mathrm{m}} K_{\mathrm{L}} C_{\mathrm{e}}}{1+K_{\mathrm{L}} C_{\mathrm{e}}}$ & -0.00232 & -29.154 & 0.744
\end{tabular}

Fruendlich nonlinear isotherm

\begin{tabular}{llll}
\hline Equation & $\mathrm{K}_{\mathrm{F}}(\mathrm{L} / \mathrm{mg})$ & $1 / n$ & $R^{2}$ \\
\hline$q_{\mathrm{e}}=K_{\mathrm{F}} C_{\mathrm{e}}^{1 / n}$ & 0.0000023 & 5.1058 & 0.8312 \\
\hline
\end{tabular}

Redlich-Peterson nonlinear isotherm

\begin{tabular}{lllll}
\hline Equation & $A$ & $B$ & $g$ & $R^{2}$ \\
\hline $\mathrm{q}_{e}=\frac{A C_{\mathrm{e}}}{1+B C_{\mathrm{e}}^{g}}$ & 0.04 & 0.05 & 0.7 & 0.7818 \\
\hline
\end{tabular}

[AR97] $=10-70 \mathrm{mg} / \mathrm{L}, \quad$ contact $\quad$ time $=60 \mathrm{~min}, \quad$ agitation speed $=140 \mathrm{rpm}$, adsorbent dose $=12 \mathrm{~g} / \mathrm{L}, \mathrm{pH}=5.45$

analysis is to relate adsorbate concentration in the solution and adsorbent surface (Khaled et al. 2009). The Langmuir, Fruendlich and Redlich-Peterson models are the most common types of isotherm equations, which were applied for analyzing experimental sorption data. The adequacy of model for predicting the experimental data was evaluated by correlation coefficient $\left(R^{2}\right)$, and the results are given in Table 1.

Langmuir isotherm

The Langmuir isotherm assumes that the highest adsorption happens when a saturated monolayer of solute molecules exists on the adsorbent surface (homogenous system). The energy of adsorption is stable, and there is no migration of adsorbate molecules in the surface plane (Senthil Kumar et al. 2010). The equation of Langmuir isotherm is represented as follows:

$q_{e}=\frac{q_{m} K_{\mathrm{L}} C_{\mathrm{e}}}{1+K_{\mathrm{L}} C_{\mathrm{e}}}$

where $q_{\mathrm{e}}$ is the equilibrium dye concentration on adsorbent $(\mathrm{mg} / \mathrm{g}), q_{\mathrm{m}}$ is the monolayer capacity of the adsorbent $(\mathrm{mg} /$ $\mathrm{g}), C_{\mathrm{e}}$ is the equilibrium dye concentration in solution ( $\mathrm{mg} /$ $\mathrm{L}$ ), and $K_{\mathrm{L}}$ is the Langmuir adsorption constant representing the energy constant related to the heat of adsorption (Senthil Kumar et al. 2010). Correlation coefficient $\left(R^{2}\right)$ of 0.744 (Table 1) indicates that this isotherm is not suitable for adsorption prediction.

Fruendlich isotherm

The Fruendlich isotherm model is an exponential equation that considering the adsorption on heterogeneous surface with interaction between adsorbed molecules and is not 
Table 2 Different kinetic model parameter

\begin{tabular}{lll}
\hline Pseudo-first order & & \\
\hline$k_{1}\left(\mathrm{~min}^{-1}\right)$ & $q_{\mathrm{e}}(\mathrm{mg} / \mathrm{g})$ & $R^{2}$ \\
\hline 0.1082 & 0.9005 & 0.9351 \\
\hline Pseudo-second order & & \\
\hline$k_{2}(\mathrm{~g} / \mathrm{mg}$ min $)$ & $q_{\mathrm{e}}(\mathrm{mg} / \mathrm{g})$ & $R^{2}$ \\
\hline 2.269 & 2.823 & 0.9994 \\
\hline Intra-particle diffusion & & \\
\hline$K_{\mathrm{i}, 1}\left(\mathrm{mg} / \mathrm{g}\right.$ min $\left.^{0.5}\right)$ & $\mathrm{I}_{1}(\mathrm{mg} / \mathrm{g}) \mathrm{able}$ & $R^{2}$ \\
0.0778 & 2.3995 & 0.9316 \\
$K_{\mathrm{i}, 2}\left(\mathrm{mg} / \mathrm{g}\right.$ min $\left.^{0.5}\right)$ & $\mathrm{I}_{2}(\mathrm{mg} / \mathrm{g})$ & $R^{2}$ \\
0.0031 & 2.8563 & 0.7914 \\
\hline
\end{tabular}

[AR97] $=50 \mathrm{mg} / \mathrm{L}, \mathrm{T}=298 \mathrm{~K}$, agitation speed $=140 \mathrm{rpm}$, adsorbent dose $=12 \mathrm{~g} / \mathrm{L}, \mathrm{pH}=5.45$

restricted to the formation of a monolayer (Nandi et al. 2009a, b). This model is given as:

$q_{\mathrm{e}}=K_{\mathrm{F}} C_{\mathrm{e}}^{1 / n}$

where $n$ and $K_{\mathrm{F}}$ are Fruendlich constants related to adsorption intensity of the adsorbent and adsorption capacity, respectively ( $\mathrm{Li}$ et al. 2010). The correlation coefficient $\left(R^{2}\right)$ values demonstrate that the adsorption isotherm for the present system is explained better by Fruendlich model $\left(R^{2}=0.8312\right)$ (Table 1$)$.

\section{Redlich-Peterson isotherm}

Combination of Langmuir and Fruendlich models makes the Redlich-Peterson isotherm. It is in accordance with the Langmuir equation at low concentration and is close to the Fruendlich model at high concentration (Senthil Kumar et al. 2010). In addition, the Redlich-Peterson equation adds three parameters into an empirical isotherm and, consequently, can be utilized both in homogenous or in heterogeneous systems because of the high versatility of the equation (Mall et al. 2006). The equation is given as:

$q_{\mathrm{e}}=\frac{A C_{\mathrm{e}}}{1+B C_{\mathrm{e}}^{\mathrm{g}}}$

where $A$ and $B$ are Redlich-Peterson isotherm constants, and $g$ is the exponent which lies between 0 and 1 . It is obvious from Table 1 that this isotherm cannot be considered as favorable isotherm $\left(R^{2}=0.8718\right)$.

\section{Adsorption kinetics}

In order to study the controlling mechanism of adsorption process, three kinetic models were investigated. Pseudo- first-order kinetic model, pseudo-second-order kinetic model and intra-particle diffusion model were applied to find the best-fitted model for the experimental data, and the obtained results are presented in Table 2 .

\section{Pseudo-first-order kinetic model}

This model is based on the assumption that the rate of solute uptake with time was directly correlative with difference in saturation concentration and the adsorbed amount. The first-order rate expression (linear form) is given as:

$\log \left(q_{\mathrm{e}}-q_{t}\right)=\log q_{\mathrm{e}}-\frac{k_{1}}{2.303} t$

where $k_{1}$ is the pseudo-first-order rate constant $\left(\mathrm{min}^{-1}\right), q_{t}$ and $q_{\mathrm{e}}$ are the amount of dye adsorbed $(\mathrm{mg} / \mathrm{g}$ ) at contact time $t(\mathrm{~min})$ and at equilibrium. The plot of $\log \left(q_{\mathrm{e}}-q_{t}\right)$ versus $t$ revealed that the adsorption process is not following the pseudo-first-order kinetic model by correlation coefficient of 0.9351 (Table 2) (Rao et al. 2011).

Pseudo-second-order kinetic model

The linear form of the pseudo-second-order kinetic model is defined as:

$\frac{t}{q_{t}}=\frac{1}{k_{2} q_{\mathrm{e}}^{2}}+\frac{t}{q_{\mathrm{e}}}$

where $k_{2}$ is the rate constant for pseudo-second-order sorption $(\mathrm{g} / \mathrm{mg} \mathrm{min})$. The straight-line plot of $t / q_{t}$ versus $t$ has been used to determine rate parameters (Ghasemi et al. 2011). The results of Table 2 showed that the highest correlation coefficient $\left(R^{2}=0.9994\right)$ among kinetic models is related to the pseudo-second-order kinetic model, and also, the calculated $q_{\mathrm{e}}$ value in this model was very close to what experimentally obtained $q_{\mathrm{e}}(2.882 \mathrm{mg} / \mathrm{g})$. Thus, the adsorption of AR97 on WS was explained better by the pseudo-second-order kinetic model.

Intra-particle diffusion model

This model is based on the hypothesis that the mechanism for dye removal by adsorption on a sorbent material occurs through four steps: (1) bulk diffusion, which is the migration of dye molecules from bulk solution to the surface of the adsorbent; (2) film diffusion, which is diffusion of dye molecules through the boundary layer to the surface of the adsorbent; (3) dye adsorption on active site of the surface of adsorbent; and (4) intra-particle diffusion, which is migration of dye to the interior pore structure of adsorbent (Doğan et al. 2009). The adsorption process is a diffusive mass transfer process where the rate can be 
Table 3 Removal of AR97 onto WS with varying temperature

\begin{tabular}{lllll}
\hline$C_{\mathrm{o}}(\mathrm{mg} / \mathrm{L})$ & \multicolumn{4}{l}{ Removal percent of dye at temperature $\left({ }^{\circ} \mathrm{C}\right)$} \\
\cline { 2 - 5 } & 18 & 30 & 40 & 50 \\
\hline 30 & 61.62 & 50.77 & 41.61 & 37.54 \\
40 & 66.55 & 61.49 & 56.5 & 46.91 \\
50 & 71.69 & 65.32 & 60.43 & 57.11 \\
60 & 73.33 & 70.21 & 65.49 & 61.82 \\
\hline [AR97] $=30-60 \mathrm{mg} / \mathrm{L}$, & contact & time $=60 \mathrm{~min}$, & agitation \\
speed $=140 \mathrm{rpm}$, adsorbent dose $=12 \mathrm{~g} / \mathrm{L}, \mathrm{pH}=5.45$
\end{tabular}

speed $=140 \mathrm{rpm}$, adsorbent dose $=12 \mathrm{~g} / \mathrm{L}, \mathrm{pH}=5.45$

expressed in terms of the square root of time $(t)$. The intraparticle diffusion model can be represented as:

$q_{\mathrm{t}}=k_{\mathrm{i}} t^{0.5}+\mathrm{I}$

where $k_{\mathrm{i}}$ is the intra-particle diffusion rate constant $(\mathrm{mg} /$ $\left.\mathrm{g} \min ^{0.5}\right)$, and $\mathrm{I}$ is the effect of boundary layer thickness (Nandi et al. 2009a, b). The $R^{2}$ value is calculated by the plot of $q_{t}$ versus $t^{0.5}$. The intra-particle diffusion plot gave multi-linearity (Table 2), indicating the different stages (Ghasemi et al. 2011).

The effect of temperature and evaluation

of thermodynamic parameters

In any adsorption process, the amounts of thermodynamic parameters are the significant indicators for practical application. To study the effect of temperature on the adsorption capacity, experiments were accomplished for four different dye concentrations (30, 40, 50 and $60 \mathrm{mg} / \mathrm{L}$ ) at various temperatures $(18,30,40$ and $50 \mathrm{C})$ using $0.6 \mathrm{~g}$ of WS. The equilibrium contact time for adsorption was maintained at $60 \mathrm{~min}$. It was observed that with increase in temperature, removal percentage decreased (Table 3). This means that the adsorption is exothermic in nature (Nandi et al. 2009a, b). The thermodynamic parameters including Gibbs free energy $\left(\Delta G^{\circ}\right)$, enthalpy $\left(\Delta H^{\circ}\right)$ and entropy $\left(\Delta S^{\circ}\right)$ for the adsorption of AR97 onto WS have been calculated by using equations as follows and presented in Table 4 (Senthil Kumar et al. 2010):

$$
\begin{aligned}
& K_{\mathrm{c}}=\frac{C_{A}}{C_{\mathrm{S}}} \\
& \Delta G^{\circ}=-\mathrm{RT} \ln K_{\mathrm{c}} \\
& \ln K_{c}=\frac{\Delta S^{\circ}}{R}-\frac{\Delta H^{\circ}}{\mathrm{RT}}
\end{aligned}
$$

\begin{tabular}{|c|c|c|c|c|c|c|}
\hline $\begin{array}{l}C_{\mathrm{o}} \\
(\mathrm{mg} / \mathrm{L})\end{array}$ & $T\left({ }^{\circ} \mathrm{C}\right)$ & $\begin{array}{l}C_{\mathrm{e}} \\
(\mathrm{mg} / \mathrm{L})\end{array}$ & $K_{c}$ & $\begin{array}{l}\Delta G^{\circ}(\mathrm{kJ} / \\
\mathrm{mol})\end{array}$ & $\begin{array}{l}\Delta H^{\circ}(\mathrm{kJ} / \\
\mathrm{mol})\end{array}$ & $\begin{array}{l}\Delta S^{\circ}(\mathrm{J} / \\
\mathrm{mol} \mathrm{K})\end{array}$ \\
\hline \multirow[t]{4}{*}{30} & 18 & 10.613 & 1.826 & -1.456 & -26.566 & -87.388 \\
\hline & 30 & 16.267 & 0.884 & 0.427 & & \\
\hline & 40 & 17.517 & 0.712 & 0.883 & & \\
\hline & 50 & 18.738 & 0.601 & 1.367 & & \\
\hline \multirow[t]{4}{*}{40} & 18 & 13.380 & 1.989 & -1.663 & -19.241 & -59.977 \\
\hline & 30 & 13.404 & 1.596 & -1.177 & & \\
\hline & 40 & 15.404 & 1.229 & -0.680 & & \\
\hline & 50 & 21.238 & 0.883 & 0.334 & & \\
\hline \multirow[t]{4}{*}{50} & 18 & 14.154 & 2.532 & -2.518 & -19.834 & -59.977 \\
\hline & 30 & 17.339 & 1.883 & -1.594 & & \\
\hline & 40 & 21.744 & 1.229 & -0.680 & & \\
\hline & 50 & 21.446 & 1.331 & -0.767 & & \\
\hline \multirow[t]{4}{*}{60} & 18 & 16 & 2.75 & -2.447 & -13.240 & -36.903 \\
\hline & 30 & 17.875 & 2.356 & -2.158 & & \\
\hline & 40 & 20.702 & 1.898 & -1.667 & & \\
\hline & 50 & 22.904 & 1.619 & -1.294 & & \\
\hline
\end{tabular}

Table 4 Thermodynamic parameters calculated for the adsorption of AR97 onto WS

where $K_{\mathrm{c}}$ is the equilibrium constant, $C_{\mathrm{S}}$ is the equilibrium concentration of the dye in the solution $(\mathrm{mg} / \mathrm{L})$, and $C_{\mathrm{A}}$ is the amount of dye adsorbed on the adsorbent in the solution at equilibrium $(\mathrm{mg} / \mathrm{L}) . R$ is the gas constant, and $T$ is the solution temperature $(K) . \Delta S^{\circ}$ and $\Delta H^{\circ}$ were obtained from the intercept and slope of Van't Hoff plot of $\ln K_{\mathrm{c}}$ versus 1/ $T$ from Eq. 12. The results are given in Table 4. The negative values of $\Delta \mathrm{G}^{\circ}$ indicated the feasibility and spontaneous nature of AR97 sorption onto WS. The value of enthalpy of a sorption process is used to determine the chemical or physical sorption. For chemical sorption, enthalpy values vary from 83 to $830 \mathrm{~kJ} / \mathrm{mol}$, and for physical sorption, they vary from 8 to $25 \mathrm{~kJ} / \mathrm{mol}$ (Govindasmay et al. 2009). It can be concluded from the low value of $\Delta \mathrm{H}^{\circ}$ that the interaction between AR97 dye molecules and WS is physical. The exothermic nature is also indicated by the negative value of $\Delta H^{\circ}$.

\section{Conclusion}

This study investigated the removal of AR97 from aqueous solution by WS under different operational conditions such as effect of adsorbent dose, agitation speed, contact time, 
$\mathrm{pH}$ and temperature. The adsorption process follows Fruendlich isotherm, which fits well heterogeneous surfaces. It was found that the adsorption mechanism follows pseudosecond-order kinetic model. BET analysis of WS showed the surface area to be $1.28 \mathrm{~m}^{2} / \mathrm{g}$. The effect of temperature was investigated to calculate thermodynamic characteristics. The analysis of these parameters revealed that the process is: (a) spontaneous, (b) exothermic and (c) mainly physical because of the low $\Delta H^{\circ}$ value, negative $\Delta G^{\circ}$ and $\Delta S^{\circ}$.

\section{References}

Altun T, Pehlivan E (2012) Removal of $\mathrm{Cr}(\mathrm{VI})$ from aqueous solutions by modified walnut shell. Food Chem 132:693-700

Behnajady MA, Vahid B, Modirshahla N, Shokri M (2006) Evaluation of electrical energy per order $\left(\mathrm{E}_{\mathrm{EO}}\right)$ with kinetic modeling on photooxidative degradation of C.I. acid orange 7 in a tubular continuous-flow photoreactor. Ind Eng Chem Res 45:553-557

Behnajady MA, Modirshahla N, Daneshvar N, Rabbani M (2007) Photocatalytic degradation of an azo dye in a tubular continuousflow photoreactor with immobilized $\mathrm{TiO}_{2}$ on glass plates. Chem Eng J 127:167-176

Behnajady MA, Modirshahla N, Shokri M, Vahid B (2008) Effect of operational parameters on degradation of malachite green by ultrasonic irradiation. Ultrason Sonochem 15:1009-1014

Cao JSh, Lin JX, Fang F, Zhang MT, Hu ZR (2014) A new absorbent by modifying walnut shell for the removal of anionic dye: kinetic and thermodynamic studies. Bioresour Technol 163:199-205

Dahri MK, Rahimi Kooh MR, Lim LBL (2014) Water remediation using low cost adsorbent walnut shell for removal of malachite green: equilibrium, kinetics, thermodynamic and regeneration studies. J Environ Chem Eng 2:1434-1444

Daneshvar N, Rabbani M, Modirshahla N, Behnajady MA (2004) Kinetics modeling of photocatalytic degradation of acid red 27 in $\mathrm{UV} / \mathrm{TiO}_{2}$ process. J Chem Technol Biotechnol 168:39-45

Demirbas A (2009) Agricultural based activated carbons for the removal of dyes from aqueous solutions: a review. J Hazard Mater 167:1-9

Doğan M, Alkan M, Türkyilmaz A, Özdemir Y (2004) Kinetics and mechanism of removal of methylene blue by adsorption onto perlite. J Hazard Mater B 109:141-148

Doğan M, Abak H, Alkan M (2009) Adsorption of methylene blue onto hazelnut shell: kinetics, mechanism and activation parameters. J Hazard Mater 164:172-181

Dural MU, Cavasa L, Papageorgiouc SK, Katsaros FK (2010) methylene blue adsorption on activated carbon prepared from Posidonia oceanica (L.) dead leaves: kinetics and equilibrium studies. Chem Eng J 165:77-85

Eren E, Cubuk O, Ciftci H, Eren B, Caglar B (2010) Adsorption of basic dye from aqueous solutions by modified sepiolite: equilibrium, kinetics and thermodynamics study. Desalination 252:88-96

Furlan FR, Silva LG, Morgado AF, Souza AA, Souza SM (2010) Removal of reactive dyes from aqueous solutions using combined coagulation/flocculation and adsorption on activated carbon. Resour Conserv Recycl 54:283-290

Ghasemi Z, Seif A, Ahmadi TS, Zargar B, Rashidi F, Rouzbahani GM (2011) Thermodynamic and kinetic studies for the adsorption of $\mathrm{Hg}$ (II) by nano- $\mathrm{TiO}_{2}$ from aqueous solution. Adv Powder Technol 23:148-156

Gong R, Ding Y, Li M, Yang C, Liu H, Sun Y (2005) Utilization of powdered peanut hull as biosorbent for removal of anionic dyes from aqueous solution. Dyes Pigm 64:187-192

Govindasmay V, Sahadevan R, Subramanian S, Mahendradas DK (2009) Removal of malachite green from aqueous solution by perlite. Int J Chem React Eng 7:43-49

Gupta GS, Prasad G, Singh VN (1990) Removal of chrome dye from aqueous solutions by mixed adsorbents: fly ash and coal. Water Res 24:45-50

Ince $\mathrm{NH}$, Tezcanli-Güyer $\mathrm{G}$ (2004) Impact of $\mathrm{pH}$ and molecular structure on ultrasonic degradation of azo dyes. Ultrasonics 42:591-596

Jain S, Jayaram RV (2010) Removal of basic dyes from aqueous solution by low-cost adsorbent: wood apple shell (Feronia acidissina). Desalination 250:921-927

Kayan B, Gözmen B, Demirel M, Gizir AM (2010) Degradation of acid red 97 dye in aqueous medium using wet oxidation and electro-Fenton techniques. J Hazard Mater 177:95-102

Khaled A, El Nemr A, El-Sikaily A, Abdelwahab O (2009) Treatment of artificial textile dye effluent containing direct yellow 12 by orange peel carbon. Desalination 238:210-232

Ledakowicz S, Solecka M, Zylla R (2001) Biodegradation, decolourisation and detoxification of textile wastewater enhanced by advanced oxidation processes. J Biotechnol 89:175-184

Li Q, Yue QY, Su Y, Gao BY, Sun HJ (2010) Equilibrium, thermodynamics and process design to minimize adsorbent amount for the adsorption of acid dyes onto cationic polymerloaded bentonite. Chem Eng J 158:489-497

Mall ID, Srivasava VC, Agarwal NK (2006) Removal of orange- g and methyl violet dyes by adsorption onto bagasse fly ash-kinetic study and equilibrium isotherm analyses. Dyes Pigm 69:210-223

Mustafaa F, Al-Ghoutib MA, Khalili FI, Al-Degsc YS (2010) Characteristics of organosulphur compounds adsorption onto Jordanian zeolitic tuff from diesel fuel. J Hazard Mater 182:97-107

Nandi BK, Goswami A, Purkait MK (2009a) Adsorption characteristics of brilliant green dye on kaolin. J Hazard Mater 161:387-395

Nandi BK, Goswami A, Purkait MK (2009b) Removal of cationic dyes from aqueous solutions by kaolin: kinetic and equilibrium studies. Appl Clay Sci 42:583-590

Neamtu M, Yediler A, Siminiceanu I, Macoveanu M, Kellrup A (2004) Decolorization of disperse red 354 azo dye in water by several oxidation processes- a comparative study. Dyes Pigm 60:61-68

Rafatullah M, Sulaiman O, Hashim R, Ahmad A (2010) Adsorption of methylene blue on low-cost adsorbents: a review. J Hazard Mater 177:70-80

Rao RAK, Khan MA, Rehman F (2011) Batch and column studies for the removal of lead (II) ions from aqueous solution onto lignite. Adsorpt Sci Technol 29:83-98

Senthil Kumar P, Ramalingam S, Senthamarai C, Niranjanaa M, Vijayalakshmi P, Sivanesan S (2010) Adsorption of dye from aqueous solution by cashew nut shell: studies on equilibrium 
isotherm, kinetics and thermodynamics of interactions. Desalination 261:52-60

Sing KSW, Everett DH, Haul RA, Moscou L, Pierotti RA, Rouquerol J, Siemieniewska T (1985) Reporting physisorption data for gas/ solid systems with special reference to the determination of surface area and porosity. Pure Appl Chem 57: 603-619
Sun D, Zhang X, Wu Y, Liu X (2010) Adsorption of anionic dyes from aqueous solution on fly ash. J Hazard Mater 181:335-342 Wang LH, Lin ChI, Wub FCh (2010) Kinetic study of adsorption of copper (II) ion from aqueous solution using rice hull ash. J Taiwan Inst Chem E 41:599-605 